\title{
SINALIZAÇÃO DE INCONSISTÊNCIAS A PARTIR DO PATRIMÔNIO DECLARADO DE POLÍTICOS NO BRASIL: Aplicação da Lei Newcomb-Benford ${ }^{1}$
}

\section{SINALING OF INCONSISTENCES FROM THE DECLARED PATRIMONY OF POLITICIANS IN BRAZIL: Application of Newcomb-Benford}

\author{
Jonatas Dutra Sallaberry \\ Doutorando em Contabilidade \\ Universidade Federal de Santa Catarina \\ jonatas.sallaberry@hotmail.com \\ Leonardo Flach \\ Doutor em Administração pela UFRGS \\ Universidade Federal de Santa Catarina \\ leonardo.flach@gmail.com \\ Mauricio Mello Codesso \\ Doutor em Administração e Mestre em Contabilidade pela UFSC \\ Rutgers Business School - Rutgers University \\ mauricio.codesso@rutgers.edu

\section{Luiz Fernando Rodrigues} \\ Pós-Graduação em Ciências Contábeis - UFPB, UFRN e UnB \\ Universidade Católica de Brasília \\ luizfr@gmail.com
}

Mestre em Ciências Contábeis pelo Programa Multi-institucional e Inter-regional de

\section{RESUMO}

Objetivo: Buscar indícios de inconsistências ou sinalização de eventuais fraudes ou outros ilícitos financeiros nos bens declarados pelos candidatos a cargos políticos por meio da aplicação da Lei Newcomb-Benford (NB).

Fundamento: A pesquisa de natureza principalmente empírica fundamenta-se na capacidade da informação patrimonial ser útil à análise de fatos econômico-financeiros, bem como na capacidade da Lei NB sinalizar potenciais distorções na declaração de bens, considerando a distribuição observada e a esperada.

Método: Aplica-se a Lei NB, em relação aos primeiros dígitos dos valores dos bens, comparando a distribuição observada com a distribuição esperada, a partir de testes e indicadores estatísticos (Nigrini, 2012). Em segundo momento, os dígitos discrepantes são analisados mediante a relevân-

\footnotetext{
${ }^{1}$ Artigo recebido em: 24/09/2018. Revisado por pares em: 26/10/2018. Reformulado em: 27/01/2019. Revisado por pares em: 21/03/2019. Recomendado para publicação em: 31/07/2019 por Robson Zuccolotto (Editor Adjunto). Publicado em: 02/09/2019. Organização responsável pelo periódico: UFPB
} 
cia dos desvios de quantidade e valor (Bugarin \& Cunha, 2015). A aplicação dos critérios indicados pela NB e do desvio de médias permite identificar os itens de bens declarados potencialmente inconsistentes.

Resultados: A análise de primeiros dígitos permitiu identificar seis dígitos discrepantes, sendo dois que divergem em quantidade superior ao esperado. Detalhadamente, após aplicação dos métodos, nesses dígitos identificou-se bens potencialmente com valores de primeiros dígitos inconsistentes, entre os quais dinheiro declarado em espécie em moeda estrangeira e nacional, considerados bens típicos de uso em lavagem de dinheiro.

Contribuições: Os resultados da pesquisa demonstram a utilidade da aplicação da Lei NB aos órgãos de controle na busca de indícios de bens com valores potencialmente inconsistentes ou fraudados, e avança além da indicação da convergência à NB para revelar os itens divergentes dentro da amostra.

PALAVRAS-CHAVE: Lei Newcomb-Benford; Fraude; Eleições; Dinheiro em Espécie.

\section{ABSTRACT}

Objective: to search evidence of inconsistencies or for possible fraud or other financial illicit acts in the assets declared by candidates for political office through the application of the NewcombBenford Law (NB).

Background: research of a empirical nature is based on the ability of the information to be useful to analyze economic-financial facts, and too as on the ability of NB Law to signal potential deviations between the observed and expected distribution.

Method: The work use NBL applies, in relation to the first digits of the values of the assets, comparing the observed distribution with the expected distribution from statistical tests and indicators (Nigrini, 2012). Second, discrepant digits are analyzed by the relevance of quantity and value deviations (Bugarin \& Cunha, 2015). The application of the criteria indicated by NB and the deviation of averages allows to identify the items of declared goods potentially inconsistent.

Results: The individualized first-digit analysis allowed us to identify six digits that differed from the expected distribution, two of which diverged more than expected. In detail, following the application of the methods, these items were identified as potentially possessing inconsistent firstdigit values, including money declared in cash in foreign and domestic currency, considered to be typical goods used in money laundering.

Contributions: The results of the research demonstrate the utility application the NB Law to the control organs in the search for evidence of assets with potentially inconsistent or fraudulent values and advances beyond the convergence statement to NB to reveal the divergent items within the sample.

KEYWORDS: Newcomb-Benford Law; Fraud; Elections; Cash.

\section{INTRODUÇÃO}

O cenário político brasileiro tem proporcionado situações no mínimo impróprias de seus integrantes, desde relações conflitantes com a ética até a apropriação do patrimônio público por seus agentes. Esses fatos costumam ser denunciados durante todo o mandato eleitoral de um político corrupto, no entanto nos anos eleitorais as críticas, devidas e indevidas, se acirram evidenciando diversas práticas delituosas.

As principais discussões no que tange a práticas indevidas em campanhas eleitorais são a compra de votos, a venda de vagas, o uso indevido da máquina pública e o uso de recursos ilícitos (caixa dois), decorrente de corrupção política, tráfico de influência, abuso de poder econômico 
(Rodrigues \& Sallaberry, 2013). As escassas pesquisas empíricas sobre os recursos envolvidos em campanhas eleitorais têm abarcado tão somente as receitas e despesas de campanha, assim como as verificações dos Tribunais Eleitorais quanto as origens e destinos imediatos dos recursos que transitam pelas campanhas.

No entanto as informações disponíveis à sociedade são mais amplas, permitindo conhecer mais de perto os candidatos pelos seus dados pessoais e de perfil. Entre os dados dos candidatos que podem ser analisados estão as informações de qualificação, profissionais e patrimoniais, onde são declarados por ocasião das candidaturas os bens pessoais. A posse, controle e benefícios dos ativos não são necessariamente ilicitudes, mas podem sinalizar indícios de inconsistências, ou destino de crimes, como enriquecimento ilícito, ocultação de bens, corrupção, caixa dois, entre outras tipificações criminais.

Diante das notórias condutas indevidas de políticos brasileiros e do potencial que as informações patrimoniais têm para elucidação de crimes financeiros, a presente pesquisa admite como problema de pesquisa a necessidade de se identificar bens com indícios de inconsistências, que podem revelar origem ilícita entre o patrimônio declarado dos candidatos a cargo eletivo.

No intuito de buscar identificar bens inconsistentes, que pode indicar bens fraudulentos, propõe-se como objetivo identificar sinalizadores de distorções patrimoniais nos bens declarados pelos candidatos a cargos públicos a partir da aplicação da Lei Newcomb-Benford (NB). Tal aplicação da distribuição teórica dos primeiros dígitos da Lei NB na distribuição real dos primeiros dígitos dos bens dos candidatos tende a demonstrar itens que potencialmente sofreram gerenciamento de valores para fins de declaração aos Tribunais Eleitorais, que podem ser indícios significativos de fraudes eleitorais.

Kassen e Higson (2016) sugerem que estudos devem explorar as diferentes técnicas de auditoria que possam ajudar os controladores a avaliar e responder aos riscos de corrupção. Antes, Healy e Serafeim (2011) apontaram para a importância dos esforços anticorrupção, suas causas e consequências. A aplicação da técnica de investigação e de seus achados pode contribuir com a análise de investigadores de órgãos de controle, auditores de contas eleitorais bem como pesquisadores e cidadãos no exercício do controle social.

\section{DESENVOLVIMENTO}

Zovatto (2005) elenca entre os principais problemas vinculados à relação entre financiamento político e a corrupção na América Latina, como o recebimento de contribuições que infringem as regulamentações existentes, o uso de recursos derivados de atividades corruptas, e a aceitação de contribuições de fontes questionáveis. Nassmacher (1992) identifica na prática mundial comparada a relevância da transparência, que enfatiza a importância do acesso público à informação relacionada com as finanças partidárias de forma que os eleitores assumam suas responsabilidades e liberdades, e assim façam uma escolha informada.

A análise de itens patrimoniais atrai a necessidade do conhecimento contábil e a competência do profissional contábil. Nesse esforço, a Contabilidade é a linguagem dos negócios na qual os principais agentes econômicos buscam informações de natureza econômico-financeira, inclusive no âmbito da Contabilidade Eleitoral (Rodrigues \& Sallaberry, 2013). No mesmo direcionamento Santos et al. (2004) Reforçam essa aplicação ao indicar que o objetivo da contabilidade pode ser estabelecido como o de fornecer informações como suporte à tomada de decisão, corroborando também Iudícibus e Marion (2000).

A evidenciação contábil é uma prática que reduz o grau de assimetria de informação e de incerteza, possibilitando ao eleitor e aos órgãos de controle bases mais confiáveis para a tomada de decisões. Colocar à disposição da sociedade a informação sobre os aspectos financeiros eleitorais e 
conhecimento sobre essas informações é uma forma de "empoderamento" da sociedade (Rodrigues \& Sallaberry, 2013).

De acordo com Bushman et al. (2004), é preciso que informações estejam acessíveis aos interessados para ser caracterizada a transparência. $\mathrm{O}$ ato de prestar contas é mais uma exigência legal que pode ser entendida como uma obrigação dos candidatos perante a sociedade.

Em virtude dessa vasta utilidade que a contabilidade propicia aos seus usuários, diversos segmentos se utilizam de informações produzidas pela contabilidade mesmo que seu objetivo não seja comercial, como é o caso dos partidos políticos e dos candidatos que precisam auferir receitas e realizar despesas, e também da sociedade que deve zelar por práticas honestas entre seus representantes (Rodrigues \& Sallaberry, 2013).

Nesse escopo, a prestação de contas evidencia bens, receitas e despesas das candidaturas, permitindo uma maior participação social, política e judicial na escolha eleitoral. Há muito tempo o Banco Mundial, 1994, recomenda para o combate a corrupção a adoção do processo de auditoria, tendo por base um forte arcabouço jurídico, a adoção e aplicação de normas contábeis de qualidade, um sistema de informações e por fim, uma base de auditores contábeis para execução do processo (Everett, Neu, \& Rahaman, 2007; Vechia, 2018).

A auditoria aplicada no cenário eleitoral reduz a corrupção visto que aumentam a percepção dos custos para os políticos (Avis, Ferraz, \& Finan, 2016). Por meio da auditoria é possível realizar um exame sistemático dos dados, a fim de verificar se eles foram executados de acordo com o que foi regulamento na legislação eleitoral; ela fornece dados que são essenciais para o controle e prevenção de atividades corruptas (Barkemeyer, Preuss, \& Lee, 2015; Vechia et al., 2018).

A aplicação de técnicas de auditoria pode auxiliar os auditores a avaliar e responder aos riscos de corrupção bem como à legalidade da prestação de contas e dos recursos geridos (Kassen \& Higson, 2016). Por meio da auditoria contábil que seria possível examinar os tipos de inconsistências ou fraudes cometidas, como cada uma foi cometida e detectada, bem como a mensuração da fraude.

\subsection{Evidenciação Eleitoral Quanto aos Bens}

A atuação do profissional e a regulamentação contábil são tradicionalmente vinculadas às prestações de contas, de receitas e despesas, com vasto arcabouço. A Lei n 9.096/1995, em seu artigo 30, prevê que constituem obrigações dos partidos políticos, por meio de seus órgãos, manter escrituração contábil, sob responsabilidade de profissional habilitado em contabilidade, de forma a permitir a aferição da origem de suas receitas e a destinação de suas despesas, bem como a aferição de sua situação patrimonial (Rodrigues \& Sallaberry, 2013).

A Resolução $n^{\circ}$ 21.841/2004-TSE, que disciplinou a prestação de contas dos partidos políticos e a tomada de tontas especial, em seu artigo $2^{\circ}$, prevê que os estatutos dos partidos políticos, associações civis sem fins econômicos, devem conter normas sobre finanças e contabilidade, em consonância com os princípios de contabilidade e às Normas Brasileiras de Contabilidade (Rodrigues \& Sallaberry, 2013).

Especificamente, em relação ao processo de campanha eleitoral, a cada dois anos, a obrigação da declaração dos bens é estabelecida por meio do inciso IV, $\S 1^{\circ}$, art. 11 da Lei 9.504/97, o qual discorre:

Art. 11. Os partidos e coligações solicitarão à Justiça Eleitoral o registro de seus candidatos até as dezenove horas do dia 15 de agosto do ano em que se realizarem as eleições.

$\S 1^{\circ} \mathrm{O}$ pedido de registro deve ser instruído com os seguintes documentos:

[...]

IV - declaração de bens, assinada pelo candidato;

$\mathrm{V}$ - cópia do título eleitoral ou certidão, fornecida (...) 
No entanto o controle judiciário não parece ser eficaz, pois somente estabelece como medida corretiva genérica a possibilidade de correção em prazo de 72 horas ou 3 dias, conforme o $\S 3^{\circ}$, art. 11 da Lei 9.504/97, "Caso entenda necessário, o Juiz abrirá prazo de setenta e duas horas para diligências", melhor detalhado no art. 37 da Resolução 23.548/2017, como segue:

Art. 37. Constatada qualquer falha, omissão ou ausência de documentos necessários à instrução do pedido, inclusive no que se refere à inobservância dos percentuais previstos no $\S 4^{\circ}$ do art. 20, o partido político, a coligação ou o candidato será intimado, de ofício, pela Secretaria Judiciária, para que o vício seja sanado no prazo de 3 (três) dias, na forma prevista nesta resolução (Lei n⿳o 9.504/1997, art. 11, § $3^{\circ}$ ).

A arrecadação de recursos pelos partidos políticos, seus candidatos e comitês financeiros é disciplinada, seja pelas Leis no 9.096/95 e 9.504/97 ou pelas sucessivas Resoluções do TSE que estabelecem parâmetros para cada eleição (Sallaberry, Vendruscolo, \& Rodrigues, 2014). Embora não haja disposição específica, Mattos, Mendes e Rios (2012) destacam que esses recursos não podem extrapolar os limites máximos de gastos estabelecidos pelo partido e informado à Justiça Eleitoral por ocasião do registro de candidatura, além da possibilidade de exigência da comprovação da origem dos valores aplicados em sua própria campanha.

A informação dos bens dos candidatos é declarada eletronicamente no momento do registro da candidatura, por meio do Sistema de Candidaturas - Módulo Externo (CANDex). Nesse momento o sistema exige que se informae se o candidato possui bens a declarar, o tipo de bem, e o valor do bem. As categorias de bens disponíveis para declaração são diversos, o que não seria motivos para omissões, desde itens mais comuns como dinheiro em espécie, bens móveis e depósitos em conta ou poupança, até itens menos comuns, como aeronaves, depósito bancário no exterior ou moeda estrangeira em espécie, direito de autor, inventor e patente, até obras raras, de coleção e antiguidades.

Independente de se tratar de recursos próprios do candidato, ou de origem de terceiros, os recursos financeiros que transitam como receitas e despesas das campanhas eleitorais são informados eletronicamente por meio do Sistema de Prestação de Contas Eleitorais (SPCE), inclusive aqueles originados dos recursos próprios ou de terceiros candidatos, ainda que convertidos em bens ou serviços estimáveis em dinheiro (Rodrigues \& Sallaberry, 2013).

A propriedade, posse, fruição ou disposição dos próprios bens é atividade lícita, e enquanto empregada no processo eleitoral manifesta o aspecto democrático da função social do patrimônio. Todavia o que é reprimível e demanda esforço da ciência em contribuir com a prática profissional é o emprego de bens de origem ilícita como se bens lícitos fossem, o que pode ser caracterizada como a lavagem de dinheiro (Walker, 1999).

O crime conhecido como "caixa-dois", quando o recurso é arrecadado sem contabilização devida e empregado para quitar gastos de campanha (Fux \& Frazão, 2016), muitas vezes nem passa pelos registros dos bens. No entanto, em alguns casos, o processo de lavagem do dinheiro já ocorreu em etapa anterior ou está em andamento durante o processo eleitoral, e poderá ser evidenciado entre os bens declarados por ocasião do registro da campanha.

Considerando que o valor dos bens declarado não fosse objeto de uma gestão intencional do seu declarante, mas representasse a manifestação econômica, cujo valor é evidenciado algebricamente em números, espera-se que a distribuição dos valores declarados seja semelhante à distribuição prevista na Lei Newcomb-Benford (NB).

A hipótese teórica alternativa consiste em eventuais divergências entre a distribuição dos valores declarados e a distribuição da NB, que pode indicar que a distribuição desses bens segue um outro determinado comportamento, ou falhas sistêmicas, ou erros de processamento, ou mes- 
mo indícios de fraude (Nigrini, 2012). Em outros termos, essas inconsistências podem partir de erros de declaração ou de mensuração dos bens declarados (Rodrigues \& Sallaberry, 2013), ou de erros por falha na gestão ou decorrentes de atos ilícitos como fraudes (Avis et al., 2016).

Assim, para fins desta pesquisa, pode-se formular basicamente as hipóteses para comparação das distribuições esperada e observada:

$\mathrm{H}_{0}$ - Não existe diferença estatisticamente significativa entre as probabilidades observadas e esperadas;

$\mathrm{H}_{1}$ - Existe diferença estatisticamente significativa entre as probabilidades observadas e esperadas.

Discricionariamente, para posterior análise descritiva de dígitos, são empregadas variáveis para detalhamento e busca de divergências descritivas, sendo sexo/gênero, cor/raça, grau de instrução, cargo e unidade da federação empregados por disponibilidade dessas variáveis.

A variável sexo/gênero já foi considerada por Horta, Dufloth e Freitas (2016), e Avis et al. (2016), enquanto a cor/raça foi indicada por Avis, Ferraz, Finan e Varjão (2017) e Barros, Sauerbronn e Ayrosa (2012) como características que influenciam a intenção de voto. A variável nível de instrução já foi considerada por Horta et al. (2016), Avis et al. (2017) e a característica geográfica por Barros et al. (2012) em relação ao comportamento eleitoral.

Essas características que qualificam o candidato percebidas por Ferraz e Finan (2008), podem influenciar a decisão do voto segundo Nicolau (2006), no entanto busca-se tão somente elementos para análise comparativa de variações quantitativas de bens, nas diferentes características qualitativas.

\section{MÉTODO DE PESQUISA}

A metodologia empregada neste trabalho foi de estudo exploratório sobre tema até então inexplorado pela literatura acadêmica, desenvolvido com objetivo de proporcionar uma visão geral de forma metódica e organizada em fases utilizando-se de um conjunto de procedimentos intelectuais e técnicos dos quais depende a investigação científica (Gil, 1999).

A partir da análise de registros de banco de dados, o estudo exploratório proporciona maiores informações sobre o assunto a ser investigado, facilita a delimitação do tema, orienta a fixação de objetivos e a delimitação das hipóteses, além de encontrar novos enfoques sobre o assunto; assim seus resultados podem formar a base para futuras investigações (Walliman, 2005). Quanto à abordagem do problema, o trabalho visa apresentar a análise estatística dos dados, com medidas descritivas tradicionais e pela aplicação de Lei NB sobre os primeiros dígitos dos valores de bens declarados.

Os dados coletados para o estudo foram extraídos do banco de dados abertos do Tribunal Superior Eleitoral [TSE] (disponível em http://www.tse.jus.br/), em junho de 2018, nos arquivos de Candidatos e de Bens. Os dados selecionados foram intencionalmente da campanha eleitoral de 2014, cujos pleitos são nacionais e estaduais, mais próximos, em virtude da limitação dos dados de 2018, que até o desenvolvimento das pesquisas foi disponibilizado com qualidade bastante reduzida. A amostra contendo o total de bens declarados no ano de 2014, com 83.054 observações seria grande o suficiente para aplicação da Lei NB (Santos, Diniz, \& Corrar, 2007), o que torna viável o projeto.

\subsection{Lei Newcomb-Benford (NB)}

A Lei NB representa na pesquisa a aplicação de modelo contabilométrico capaz de testar a integridade de uma distribuição de dados advindos de fenômenos contábeis, como forma de auxi- 
liar o usuário a tomar uma decisão no que tange a identificação de uma anomalia da probabilidade de ocorrência de determinados valores (Santos et al., 2007).

A Lei NB decorre de descoberta do matemático Simom Newcomb (1835-1909) que empiricamente percebeu que as consultas que começavam com pelo dígito "1" eram mais frequentes do que as demais, seguindo em ordem decrescente até o dígito "9" (Nigrini, 2012). Posteriormente Frank Benford (1938) realizou estudo mais aprofundado com mais de 20 mil observações advindas de vários cenários, como áreas dos rios, números de casas, tabelas de constantes físicas e cálculos científicos, o qual foi amplamente divulgado e por isso predomina na literatura a nomenclatura do método (Santos et al., 2007).

Outros estudos avançaram na aplicação da Lei NB, como Pinkham (1961), Carslaw (1988), Christian e Gupta (1993), Nigrini (1992, 2000, 2012), Santos, Diniz, e Ribeiro Filho (2003), Saville (2006), Santos et al. (2007), Dos Santos, Ribeiro Filho, Lagioia, Alves Filho, e Araújo (2009), Costa (2012), Costa, Dos Santos, e Travassos (2012), Bugarin e Cunha (2015), e Cella e Rech (2017), que entre outros pesquisadores trouxeram a pesquisa com aplicação da Lei NB ao nível atual, com aplicações principalmente para identificação de anomalias em conjuntos de dados.

Intuitivamente seria possível atribuir a probabilidade de ocorrência de dígitos na proporção de $1 / 9$, haja vista que os dígitos de " 1 " a " 9 " podem compor normalmente o primeiro dígito de um valor. De outra forma, a Lei NB refuta essa possibilidade e indica que essa probabilidade é maior para o dígito " 1 ", ao indicar que uma casa somente iniciará pelos dígitos de "2" a "9" na mesma proporção que o dígito "1", se na rua existirem tão somente 9 casas. Se existirem, por exemplo, 10 ou 11 casas, a proporção somente voltará a ser proporcional se na rua existirem exatamente 99 domicílios. Assim, na proposição de Newcomb-Benford, a distribuição dos quatro primeiros dígitos seguiria a seguinte frequência.

Tabela 1 - Distribuição de probabilidade de ocorrência dos primeiros quatro dígitos

\begin{tabular}{ccccccccccc}
\hline Dígito & $\mathbf{0}$ & $\mathbf{1}$ & $\mathbf{2}$ & $\mathbf{3}$ & $\mathbf{4}$ & $\mathbf{5}$ & $\mathbf{6}$ & $\mathbf{7}$ & $\mathbf{8}$ & $\mathbf{9}$ \\
\hline 1 $^{\mathrm{o}}$ Dígito & - & $30,10 \%$ & $17,61 \%$ & $12,49 \%$ & $9,69 \%$ & $7,92 \%$ & $6,69 \%$ & $5,80 \%$ & $5,12 \%$ & $4,58 \%$ \\
$2^{\mathrm{o}}$ Dígito & $11,97 \%$ & $11,39 \%$ & $10,88 \%$ & $10,43 \%$ & $10,03 \%$ & $9,67 \%$ & $9,34 \%$ & $9,04 \%$ & $8,76 \%$ & $8,50 \%$ \\
$3^{\mathrm{o}}$ Dígito & $10,17 \%$ & $10,13 \%$ & $10,09 \%$ & $10,05 \%$ & $10,01 \%$ & $9,97 \%$ & $9,94 \%$ & $9,90 \%$ & $9,86 \%$ & $9,82 \%$ \\
$4^{\mathrm{o}}$ Dígito & $10,01 \%$ & $10,01 \%$ & $10,01 \%$ & $10,00 \%$ & $9,99 \%$ & $9,99 \%$ & $9,99 \%$ & $9,99 \%$ & $9,98 \%$ & $9,98 \%$ \\
\hline
\end{tabular}

Fonte: Adaptação (Cella \& Rech, 2017; Nigrini, 2012; Saville, 2006)

Para validação estatística, a modelagem é avaliada mediante a aplicação dos testes $\chi^{2}$, para a distribuição geral, e $\mathrm{Z}$ para cada dígito independentemente. $\mathrm{O}$ desenvolvimento estatístico pode ser desenvolvido por meio de planilhas ou de softwares estatísticos, normalmente em pacotes específicos, como é o caso do STATA, aplicado complementarmente nesta análise.

Em termos bastante didáticos, Santos et al. (2007) demonstram passo-a-passo os procedimentos para execução e validação da amostra à NB, conforme demonstrado no desenvolvimento da análise. No software STATA é exigido, adicionalmente à versão padrão, a instalação dos pacotes benford, firstdigit, digdis, moremata e mgof, seguido dos comandos: "benford varname"; " firstdigit varname, percent"; e "digdis varname".

\section{ANÁLISE DOS RESULTADOS}

No universo de dados analisados, ocorreram 26.252 pedidos de registros de candidatos que declararam 83.054 bens, entre $\mathrm{R} \$ 0,00$ e $\mathrm{R} \$ 2.135 .000 .000,00$. Os procedimentos iniciais consistem na extração dos arquivos, e separação dos primeiros dígitos de cada valor, ao seguir os passos de Santos et al. (2007). Os valores foram decompostos em seus primeiros quatro dígitos. O primeiro dígito foi extraído de toda a amostra, inclusive daqueles valores entre $R \$ 0,01$ e 0,09, agrupando 83.050 
observações, já desconsideradas 4 observações declaradas com valor nulo, de $\mathrm{R} \$ 0,00$. A maior ocorrência, conforme esperado pela Lei NB, são observações com o dígito 1.

Tabela 2 - Distribuição de probabilidade observada dos primeiros quatro dígitos

\begin{tabular}{rrrrrrrrrrrr}
\hline D & Amostra & \multicolumn{1}{c}{$\mathbf{1}$} & \multicolumn{1}{c}{$\mathbf{2}$} & \multicolumn{1}{c}{$\mathbf{3}$} & $\mathbf{4}$ & \multicolumn{1}{c}{$\mathbf{5}$} & $\mathbf{6}$ & $\mathbf{7}$ & $\mathbf{8}$ & $\mathbf{9}$ & $\mathbf{0}$ \\
\hline D1 & 83050 & 25255 & 14789 & 10879 & 7808 & 7503 & 5170 & 4171 & 4211 & 3264 & 0 \\
D2 & 82441 & 5707 & 7346 & 5545 & 4986 & 12705 & 4906 & 4690 & 5505 & 4478 & 26573 \\
D3 & 81776 & 3504 & 3846 & 3820 & 3495 & 6099 & 3788 & 3700 & 4037 & 3710 & 45777 \\
D4 & 80212 & 3111 & 3221 & 3201 & 3181 & 3901 & 3236 & 3236 & 3053 & 3268 & 50804 \\
\hline
\end{tabular}

Fonte: Dados da Pesquisa

Para verificar a amostra integralmente, e testar comparavelmente à distribuição da Lei NB, emprega-se o teste $\chi^{2}$, que fornece informações para uma análise geral de todos os dígitos, com objetivo de validar a magnitude dentro de um determinado nível de significância. Assim, se não houver diferença significante, a amostra observada seguiria a distribuição proposta por NB.

Tabela 3 - Distribuição dos primeiros dígitos e teste $\chi^{2}$

\begin{tabular}{|c|c|c|c|c|c|c|c|}
\hline Amostra & $\begin{array}{c}\text { N. Casos Ob- } \\
\text { servados }\end{array}$ & $\begin{array}{l}\text { Proporção } \\
\text { Esperada }\end{array}$ & $\begin{array}{l}\text { Proporção } \\
\text { Observada }\end{array}$ & $\begin{array}{l}\text { Desvio } \\
\text { (Po-Pe) }\end{array}$ & $\begin{array}{l}\text { N. Casos } \\
\text { Esperados }\end{array}$ & $\begin{array}{c}\text { Diferença } \\
\text { (PO-PE) }\end{array}$ & $\begin{array}{c}\text { Valor Teste } \\
\chi^{2}\end{array}$ \\
\hline 1 & 25255 & 0,301 & 0,304 & 0,003 & 24998 & 257 & 2,641 \\
\hline 2 & 14789 & 0,176 & 0,178 & 0,002 & 14617 & 172 & 2,029 \\
\hline 3 & 10879 & 0,125 & 0,131 & 0,006 & 10381 & 498 & 23,866 \\
\hline 4 & 7808 & 0,097 & 0,094 & - $\quad 0,003$ & 8056 & -248 & 7,625 \\
\hline 5 & 7503 & 0,079 & 0,090 & 0,011 & 6561 & 942 & 135,264 \\
\hline 6 & 5170 & 0,067 & 0,062 & 0,005 & 5564 & -394 & 27,948 \\
\hline 7 & 4171 & 0,058 & 0,050 & 0,008 & 4817 & -646 & 86,609 \\
\hline 8 & 4211 & 0,051 & 0,051 & 0,000 & 4236 & -25 & 0,142 \\
\hline 9 & 3264 & 0,046 & 0,039 & 0,007 & 3820 & -556 & 81,007 \\
\hline Total & 83050 & & & & & & 367,130 \\
\hline
\end{tabular}

Fonte: Dados da Pesquisa

Para validação do teste $\chi^{2}$, com 9 linhas de valores, indica-se 8 graus de liberdade, que corresponde ao valor crítico de 15,507. Sendo o valor de 367,13 observado, superior a 15,507, rejeita-se a hipótese nula, de que a distribuição atenderia a Lei NB, ou seja, a distribuição observada diverge da distribuição da Lei NB.

Considerando a divergência entre a distribuição observada e a distribuição esperada pela Lei NB, constatada no teste $\chi^{2}$ e assumindo a expectativa de a distribuição deveria alinhar-se à Lei NB, partiu-se à busca de elementos sobre os recortes individuais de cada primeiro dígito, pelos seus valores individuais.

Assim, pode-se analisar as diferenças entre as distribuições segundo a Lei NB e a distribuição observada, por meio do Z-teste, medindo o grau de significância das diferenças entre o esperado da Lei NB e o observado na amostra de bens de candidatos.

A análise do primeiro dígito, com 83.050 observações, pode ser evidenciada como relativamente próxima da distribuição proposta na Lei NB. 
Tabela 4 - Distribuição do primeiro dígito observado e esperado

\begin{tabular}{ccccccccccc}
\hline Amostra & $\mathbf{1}$ & $\mathbf{2}$ & $\mathbf{3}$ & $\mathbf{4}$ & $\mathbf{5}$ & $\mathbf{6}$ & $\mathbf{7}$ & $\mathbf{8}$ & $\mathbf{9}$ \\
\hline Ocorrências & 25255 & 14789 & 10879 & 7808 & 7503 & 5170 & 4171 & 4211 & 3264 \\
Observado & 0,304 & 0,178 & 0,131 & 0,094 & 0,090 & 0,062 & 0,050 & 0,051 & 0,039 \\
Esperado NB & 0,301 & 0,176 & 0,125 & 0,097 & 0,079 & 0,067 & 0,058 & 0,051 & 0,046 \\
\hline
\end{tabular}

Fonte: Dados da Pesquisa

A proximidade pode ser percebida visualmente no gráfico seguinte.

Figura 1 - Distribuição observada e esperada

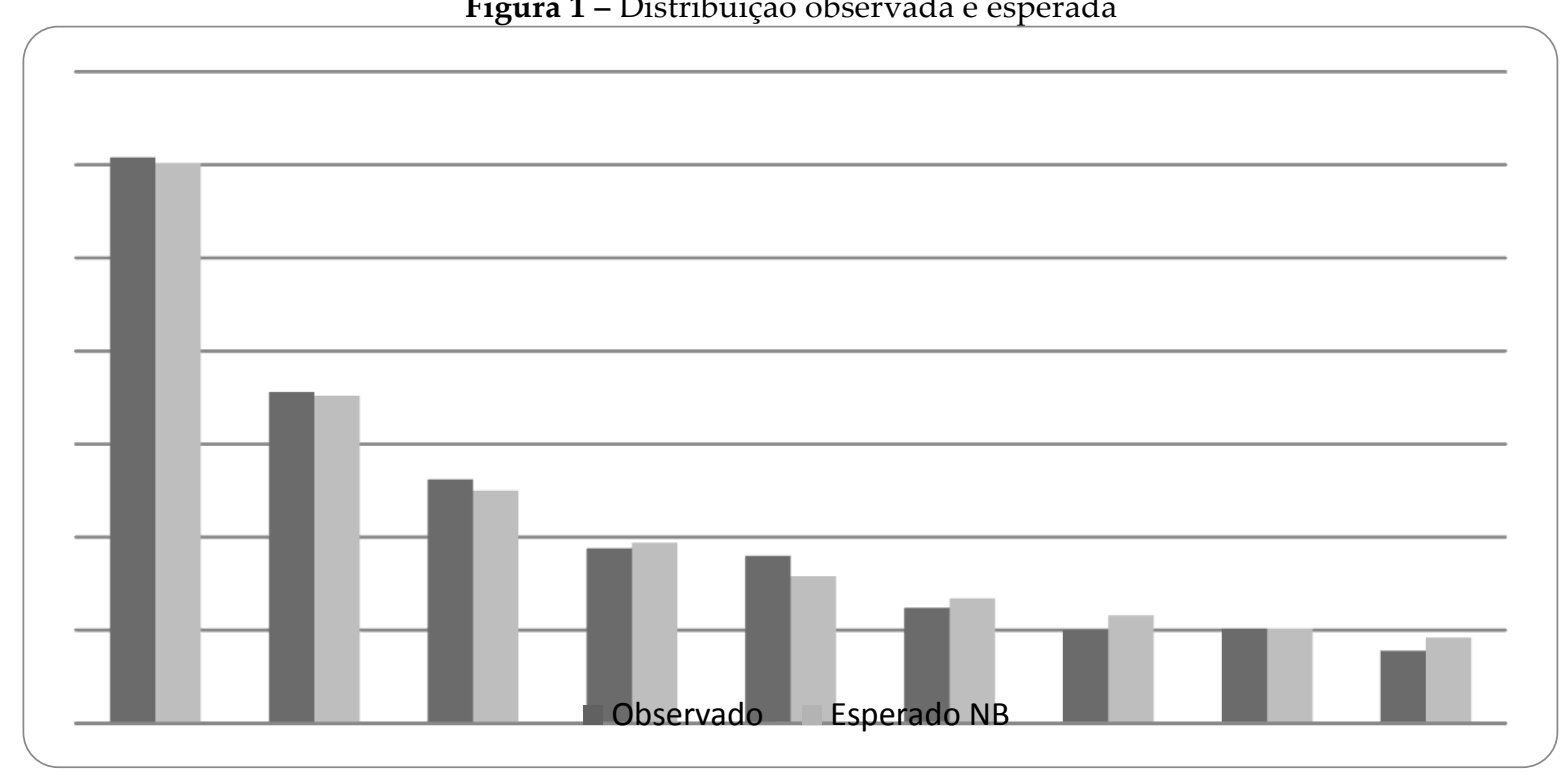

Fonte: Dados da pesquisa

A partir das observações do primeiro dígito é possível verificar a estatística $Z$, que testa se a ocorrência individual de cada valor ocorre dentro de uma margem próxima à distribuição proposta pela Lei NB. O valor tabulado para o nível de $5 \%$ em teste bilateral é de +ou-1,959, e dentro dessa lacuna, não rejeita-se a $\mathrm{H}_{0}$, permitindo inferir que a distribuição observada correspondente se alinha ao esperado da Lei NB. Fora dessa margem, indica-se que a distribuição no referido dígito é discrepante e merece maior atenção para identificar a causa do desvio.

Tabela 5 - Distribuição do primeiro dígito e teste- $Z$

\begin{tabular}{cccccccc}
\hline Amostra & $\begin{array}{c}\text { N. Casos } \\
\text { Observados }\end{array}$ & $\begin{array}{c}\text { Proporção } \\
\text { Esperada (Pe) }\end{array}$ & $\begin{array}{c}\text { Proporção } \\
\text { Observada } \\
\text { (Po) }\end{array}$ & $\begin{array}{c}\text { Desvio } \\
\text { (Po-Pe) }\end{array}$ & $\begin{array}{c}\text { N. Casos } \\
\text { Esperados } \\
\text { (PE) }\end{array}$ & Z-score & Ho \\
\hline $\mathbf{1}$ & 25255 & 0,301 & 0,304 & 0,003 & 24998 & 1,940 & Não Rejeita \\
$\mathbf{2}$ & 14789 & 0,176 & 0,178 & 0,002 & 14617 & 1,565 & Não Rejeita \\
$\mathbf{3}$ & 10879 & 0,125 & 0,131 & 0,006 & 10381 & 5,217 & Rejeita \\
$\mathbf{4}$ & 7808 & 0,097 & 0,094 & $-0,003$ & 8056 & $-2,906$ & Rejeita \\
$\mathbf{5}$ & 7503 & 0,079 & 0,090 & 0,011 & 6561 & 12,112 & Rejeita \\
$\mathbf{6}$ & 5170 & 0,067 & 0,062 & $-0,005$ & 5564 & $-5,473$ & Rejeita \\
$\mathbf{7}$ & 4171 & 0,058 & 0,050 & $-0,008$ & 4817 & $-9,589$ & Rejeita \\
$\mathbf{8}$ & 4211 & 0,051 & 0,051 & $-0,000$ & 4236 & $-0,387$ & Não Rejeita \\
$\mathbf{9}$ & 3264 & 0,046 & 0,039 & $-0,007$ & 3820 & $-9,215$ & Rejeita \\
\hline
\end{tabular}

Fonte: Dados da Pesquisa 
O teste indica que os valores iniciados com dígitos 3, 4, 5, 6, 7 e 9 tem ocorrência observada discrepante da esperada, considerando nível de significância de 5\%. Entre esses valores, apenas duas demonstram frequências superiores à distribuição esperada, de dígitos 3 e 5, enquanto as demais amostras mesmo rejeitadas (Santos et al., 2007), por denotarem a observações inferiores às esperadas, não evidenciariam elementos materiais de análise. Os valores de dígitos 3 e 5 seriam os principais alvos de uma auditoria ou investigação para determinar as causas de sua ocorrência. Essa escolha é intencional devido ao fato de que somente esses dígitos apresentaram frequência divergente, em quantidade superior à esperada.

Figura 2 - Dígitos não rejeitados excedentes

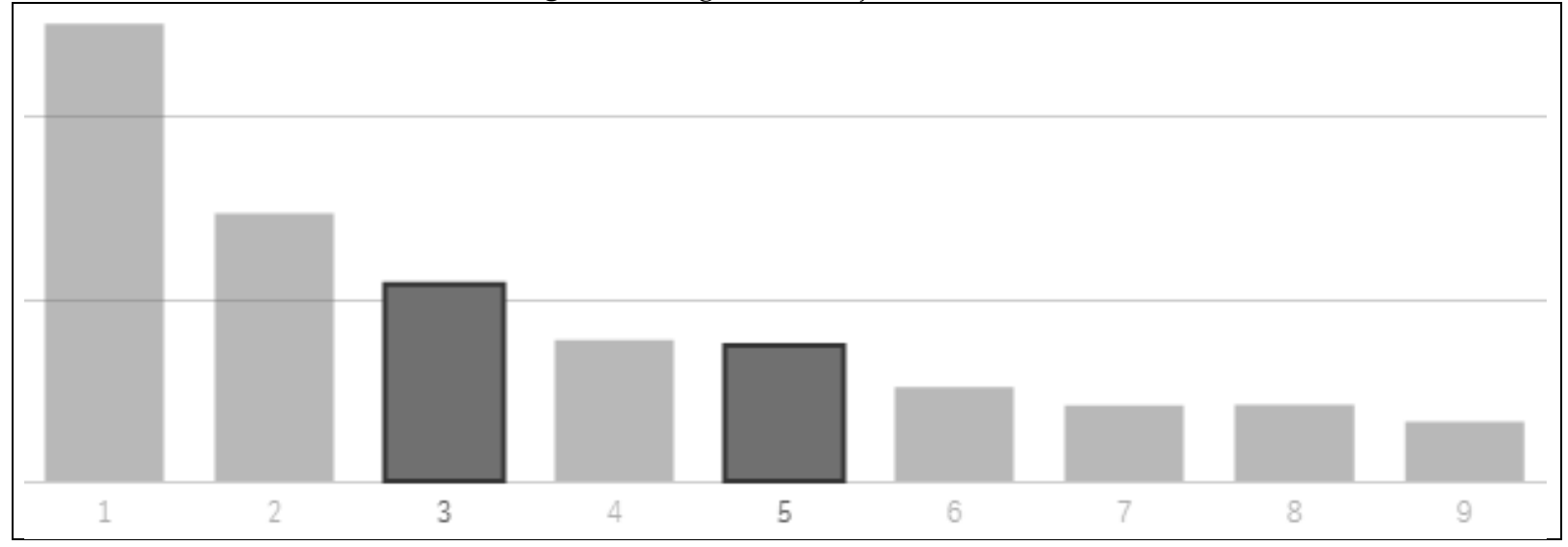

Fonte: Dados da pesquisa

Tabela 6 - Dígitos não rejeitados excedentes

\begin{tabular}{ccccccc}
\hline Dígito & $\begin{array}{c}\text { Casos Obser- } \\
\text { vados }\end{array}$ & $\begin{array}{c}\text { Proporção Ob- } \\
\text { servada }\end{array}$ & $\begin{array}{c}\text { Casos Esperados } \\
\text { NB }\end{array}$ & $\begin{array}{c}\text { Proporção Espe- } \\
\text { rada NB }\end{array}$ & $\begin{array}{c}\text { Casos Desvio } \\
\text { Proporção Des- } \\
\text { vio }\end{array}$ \\
\hline $\mathbf{3}$ & 10879 & 0,131 & 10381 & 0,125 & 498 & $5 \%$ \\
$\mathbf{5}$ & 7503 & 0,090 & 6561 & 0,079 & 942 & $13 \%$ \\
\hline
\end{tabular}

Fonte: Dados da Pesquisa

Essa proporção do desvio, demonstrada pela proporção média observada subtraindo a proporção média esperada indica a magnitude da distorção de cada dígito, permitindo comparar de forma simples tais distorções, de forma semelhante ao Fator de Distorção desenvolvido por Nigrini (1992) e aplicado por outros autores (Diniz, Corrar, \& Slomski, 2010; Costa, 2012). O Fator de Distorção (DF) quantifica a intensidade do desvio detectado; desenvolvido por Nigrini (1992), consiste em identificar a proporção do desvio na média observada $(M O)$ de uma série de dados investigada, após a imersão dos seus elementos em uma mesma ordem de grandeza, em relação à média esperada $(M E)$ para a distribuição, mediante aplicação da equação 1.

$$
D F=\left(\frac{M O-M E}{M E}\right) \times 100
$$

A Média dos Desvios Absolutos (MAD) é sugerida por Negrini (2012) para maiores bases de dados, como é o caso da presente pesquisa. A MAD da mesma forma é calculada pela diferença entre a frequência encontrada e a esperada, no entanto a razão é determinada pela quantidade de categorias de dígitos em análise, que para os primeiros dígitos, de 1 a 9 , é determinado pelo denominador 9, conforme a equação 2 . 


$$
M A D=\sum_{i=1}^{k} \frac{|F R-F E|}{k}
$$

Essa análise de conformidade não indica valores críticos, tão somente os parâmetros de Drake e Nigrini (2000), onde o resultado da soma das variações de todos os dígitos alcançou até 0,006 que indica conformidade aproximada, até 0,012 aceitável e até 0,015 como conformidade marginal aceitável. A partir de valores maiores, os autores indicaram como Não Conformidade. Após o ZTeste e o Teste Qui-quadrado, esses são os mais empregados nas pesquisas, razão pela qual foram aplicados na presente amostra.

Tabela 7 - Média dos Desvios Absolutos e Fator de Distorção

\begin{tabular}{lcccccc}
\hline Dígito & $\begin{array}{c}\text { N. Casos Ob- } \\
\text { servados }\end{array}$ & $\begin{array}{c}\text { Proporção } \\
\text { Esperada }\end{array}$ & $\begin{array}{c}\text { Proporção } \\
\text { Observada }\end{array}$ & $\begin{array}{c}\text { Diferença } \\
\text { (O - E) }\end{array}$ & MAD (/k) & FD (/E) \\
\hline $\mathbf{1}$ & 25255 & 0,301 & 0,304 & 0,003 & 0,00033 & 0,0100 \\
$\mathbf{2}$ & 14789 & 0,176 & 0,178 & 0,002 & 0,00022 & 0,0114 \\
$\mathbf{3}$ & 10879 & 0,125 & 0,131 & 0,006 & 0,00067 & 0,0480 \\
$\mathbf{4}$ & 7808 & 0,097 & 0,094 & $-0,003$ & 0,00033 & $-0,0309$ \\
$\mathbf{5}$ & 7503 & 0,079 & 0,09 & 0,011 & 0,00122 & 0,1392 \\
$\mathbf{6}$ & 5170 & 0,067 & 0,062 & $-0,005$ & 0,00056 & $-0,0746$ \\
$\mathbf{7}$ & 4171 & 0,058 & 0,05 & $-0,008$ & 0,00089 & $-0,1379$ \\
$\mathbf{8}$ & 4211 & 0,051 & 0,051 & 0 & 0,00000 & 0,0000 \\
$\mathbf{9}$ & 3264 & 0,046 & 0,039 & $-0,007$ & 0,00078 & $-0,1522$ \\
\hline
\end{tabular}

Fonte: Dados da Pesquisa

A aplicação do FD, considerando a variação em módulo, identifica que a maior discrepância encontra-se, pela ordem, nos dígitos 9, 5, 7, 6 e 3, todavia, entre esses dígitos os únicos que apresentaram proporção observada maior do que a esperada foram os dígitos 5 e 3 . Ou seja, a distorção positiva ou acima do esperado pressupõe que os itens com valores potencialmente incorretos, por erro ou fraude, estão presentes em cada amostra, e o esforço da sequência da análise consiste em identificá-los. Nos dígitos com distorção, mas com quantidade observada menor do que a esperada, pressupõe-se que os itens potencialmente incorretos estão ausentes da amostra, e portanto seria inócua uma busca aprofundada na amostra.

Na verificação da MAD, pela ordem, os maiores desvios são dos dígitos 5, 7, 9 e 3. Da mesma forma que no FD, a análise limita-se tão somente aos dígitos com desvios positivos, ou acima do esperado. No entanto, pela métrica MAD identifica-se maior relevância geral do dígito 5, com o maior desvio entre todos os dígitos. Essa discrepância entre os critérios se dá porque o denominador para o MAD é idêntico para todos os dígitos, enquanto o FD tende a favorecer os últimos dígitos que possuem no seu denominador a frequência esperada, que para os últimos dígitos é menor.

Muitas pesquisas desenvolvem-se até a aplicação dos testes estatísticos de distribuição restringindo-se a indicar se a frequência corresponde à NB e quais os dígitos discrepantes. No entanto a presente pesquisa buscou aprofundar a análise na busca empírica dos bens potencialmente com valores distintos do esperado. O montante de bens iniciados com os dígitos 3 e 5 somam 18.382 ocorrências que podem ser descritos ou classificados em grupos específicos por características de candidatos, os quais são detalhados na sequencia da análise, empregando ferramenta de Business Intelligence (BI), denominado QlikSense. Os dados são analisados descritivamente no âmbito das distribuições que ocorreram acima do esperado, de dígitos iniciais 3 e 5, que pode funcionar como 
red flags, sinalizando eventual indício de gerenciamento (Murcia, Borba, \& Schiehll, 2008), a partir dos dados disponíveis.

$\mathrm{Na}$ amostra de mais de 18 mil itens, da mesma forma se faz necessário aplicar critérios estatísticos como forma de tratamento e seleção de dados. No entanto, nessa análise em busca aplicada de "manipulação de valores", Bugarin e Cunha (2015) destacam a importância da análise da variação de quantidades e valores, procedimento selecionado para a continuidade da análise, principalmente quando essa discrepância apresenta magnitude, ele precisa ser o foco.

Em virtude da potencial exposição que a indicação de indício de anomalia poderia causar, e do escopo de análise assentado sobre o volume de bens, optou-se pela estratégia de tratar as discrepâncias pelas características demográficas dos candidatos (Avis et al., 2017; Barros et al., 2012; Horta et al., 2016).

A amostra dos itens iniciados por dígitos 3 e 5 apresenta 18382 itens, que representa 22,13\% do universo, o que, para cada subgrupo demográfico, espera-se que mantenha uma relativa paridade com essa proporção de $22,13 \%$. O critério de valores é desenvolvido por meio do critério de médias, a partir da comparação da média de valores do universo com a média da amostra, por subgrupo. Variação entre a média dos valores da amostra e as médias de valores da população podem indicar o montante adicional que encontra-se incorretamente declarado nos dígitos 3 e 5.

A amostra indica que a média dos bens declarados por mulheres é $\mathrm{R} \$ 119.493,28$, inferior a média de valores dos bens declarados por homens, de $\mathrm{R} \$ 144.769,28$. Comparativamente ao universo de bens declarados, os bens com primeiros dígitos 3 ou 5 tangenciam o percentual e 22,13\% do universo, levemente superior para as mulheres no recorte.

Os valores dos bens declarados pelas mulheres, na amostra representa $3 \%$ a maior do que a média do universo de candidatos, ainda assim, 31\% inferior ao valor médio de todos os bens declarados por candidatos do sexo masculino. A proporção e bens de mulheres corresponde a 16,19\% do total, guardando um relativo avanço ao cenário percebido por Horta et al. (2016) que constataram que a representação de mulheres passou de 10,1\% dos eleitos para apenas 13,0\%, entre 1998 e 2010.

Tabela 8 - Amostra dígitos excedentes por gênero

\begin{tabular}{ccccccc}
\hline & \multicolumn{2}{c}{ Amostra Dígitos 3 e5 } & \multicolumn{2}{c}{ Todos os Bens } & \multicolumn{2}{c}{ Relação Amostra / Total } \\
\cline { 2 - 7 } Gênero & Qtd & Média (R\$) & Qtd & Média & \% Qtd. & \% Val. Med. \\
FEMININO & 2.562 & $119.493,28$ & 11.043 & $115.593,27$ & $23 \%$ & $103 \%$ \\
MASCULINO & 15.820 & $144.769,08$ & 72.011 & $210.784,58$ & $22 \%$ & $69 \%$ \\
\hline
\end{tabular}

Fonte: Dados da Pesquisa

Analisando tão somente o universo do sexo masculino, no recorte de dígitos a média do valor dos bens de candidatos é de $\mathrm{R} \$ 144$ mil, enquanto no universo de candidatos o valor alcança $\mathrm{R} \$$ 210 mil, uma variação de $31 \%$ menor. Isto posto, percebe-se uma maior distorção no universo de bens de candidatos do sexo masculino, em relação ao universo.

A análise da cor/raça (origem) dos candidatos permite identificar que o maior valor médio declarado se refere aos 13.358 bens de posse de candidatos brancos, com média de $\mathrm{R} \$ 152.431,79$, enquanto a menor média é dos valores dos bens dos candidatos indígenas com valores médios de $\mathrm{R} \$ 26.601,84$. Em relação ao universo de bens declarados, a amostra de bens iniciados pelos dígitos 3 e 5 representam valores médios de bens declarados inferiores aos da população. 
Tabela 9 - Amostra dígitos excedentes por cor/raça

\begin{tabular}{ccccccc}
\hline & \multicolumn{2}{c}{ Amostra Dígitos 3 e 5 } & \multicolumn{2}{c}{ Todos os Bens } & \multicolumn{2}{c}{ Relação Amostra / Total } \\
\cline { 2 - 7 } Cor & Qtd & Média (R\$) & Qtd & Média (R\$) & \% Qtd. & \% Val. Med. (R\$) \\
\hline BRANCA & 13.358 & $152.431,79$ & 60.284 & $217.278,10$ & $22 \%$ & $70 \%$ \\
PARDA & 4.149 & $118.819,03$ & 18.926 & $158.656,67$ & $22 \%$ & $75 \%$ \\
AMARELA & 82 & $80.186,78$ & 347 & $96.831,42$ & $24 \%$ & $83 \%$ \\
PRETA & 768 & $78.104,56$ & 3.398 & $92.054,11$ & $23 \%$ & $85 \%$ \\
INDÍGENA & 25 & $26.601,84$ & 99 & $78.544,78$ & $25 \%$ & $34 \%$ \\
\hline
\end{tabular}

Fonte: Dados da Pesquisa

Os candidatos indígenas já apresentam menor valor médio na amostra e na população, mas mesmo assim destaca-se no recorte de dígitos 3 e 5 que os valores dos bens de indígenas representam apenas $34 \%$ da média do universo de candidatos indígenas. Em virtude disso, o critério de indígena do candidato é o fator com maior divergência (66\%) entre os bens dos candidatos por cor/raça.

Empregando como proxy de valores o grau de instrução dos candidatos, o maior valor médio de bens refere-se a candidatos com ensino fundamental incompleto, representados por 282 bens com valor médio de $R \$ 360.352,93$. Assim como demais variáveis analisadas, a relação entre a quantidade da amostra sob suspeição e o universo de bens se mantém estável entre 20 e $25 \%$ do total. A média do universo de todos os dígitos para candidatos com ensino fundamental incompleto alcança o valor médio de $\mathrm{R} \$ 179.869,31$, pouco mais do dobro do valor de $\mathrm{R} \$ 360.352,93$ da amostra iniciada por dígitos 3 e 5, o que sinaliza como uma das possibilidades significativas de ser causa do desvio da distribuição dos dígitos em relação a Lei NB.

Tabela 10 - Amostra dígitos excedentes por grau de instrução

\begin{tabular}{|c|c|c|c|c|c|c|}
\hline \multirow[b]{2}{*}{ Grau de Instrução } & \multicolumn{2}{|c|}{ Amostra Dígitos 3 e 5} & \multicolumn{2}{|c|}{ Todos os Bens } & \multicolumn{2}{|c|}{ Relação Amostra / Total } \\
\hline & Qtd & Média (R\$) & Qtd & Média (R\$) & $\%$ Qtd. & \% Val. Med. (R\$) \\
\hline SUPERIOR INCOMPLETO & 1.299 & $141.616,21$ & 5.999 & $538.141,89$ & $22 \%$ & $26 \%$ \\
\hline ENSINO FUND. COMPLETO & 709 & $138.090,35$ & 3.182 & $199.445,04$ & $22 \%$ & $69 \%$ \\
\hline ENSINO MÉDIO INCOMPLETO & 233 & $130.664,34$ & 1.112 & $183.388,78$ & $21 \%$ & $71 \%$ \\
\hline ENSINO FUND. INCOMPLETO & 282 & $360.352,93$ & 1.309 & $179.869,31$ & $22 \%$ & $200 \%$ \\
\hline ENSINO MÉDIO COMPLETO & 3.013 & $134.459,49$ & 13.556 & $177.431,92$ & $22 \%$ & $76 \%$ \\
\hline SUPERIOR COMPLETO & 12.785 & $138.669,45$ & 57.620 & $168.665,78$ & $22 \%$ & $82 \%$ \\
\hline LÊ E ESCREVE & 61 & $72.843,81$ & 276 & $105.764,31$ & $22 \%$ & $69 \%$ \\
\hline
\end{tabular}

Fonte: Dados da Pesquisa

No recorte de bens, por cargo concorrido durante a eleição, os maiores valores correspondem a bens declarados pelos $1^{\mathrm{o}}$ suplentes, cujo valor médio dos 353 bens alcançou R $\$ 449.101,85$. Esses candidatos são os que possuem bens com maior valor médio, inclusive no universo analisado para todos os dígitos, que chega a $\mathrm{R} \$ 940.468,78$. Analisando a variação do valor médio, a maior diferença foi de $58 \%$ menor da amostra de dígitos 3 e 5 em relação ao universo de todos os dígitos dos bens de candidatos ao cargo de Senador. 
Tabela 11 - Amostra dígitos excedentes por cargo pretendido

\begin{tabular}{ccccccc}
\hline & \multicolumn{2}{c}{ Amostra Dígitos 3 e 5 } & \multicolumn{2}{c}{ Todos os Bens } & \multicolumn{2}{c}{ Relação Amostra / Total } \\
\cline { 2 - 7 } Cargo & Qtd & Média (R\$) & Qtd & Média & \% Qtd. & \% Val. Med. \\
\hline 10 SUPLENTE & 353 & $449.101,85$ & 1.507 & $940.468,78$ & $23 \%$ & $48 \%$ \\
SENADOR & 421 & $353.041,05$ & 1.884 & $833.734,50$ & $22 \%$ & $42 \%$ \\
GOVERNADOR & 410 & $293.741,68$ & 1.883 & $298.332,59$ & $22 \%$ & $98 \%$ \\
2 $^{\mathbf{0}}$ SUPLENTE & 183 & $256.093,42$ & 901 & $254.121,31$ & $20 \%$ & $101 \%$ \\
VICE-GOVERNADOR & 320 & $231.862,20$ & 1.428 & $218.828,97$ & $22 \%$ & $106 \%$ \\
DEPUTADO FEDERAL & 5.495 & $144.814,43$ & 25.068 & $180.947,18$ & $22 \%$ & $80 \%$ \\
VICE-PRESIDENTE & 21 & $117.210,73$ & 84 & $179.766,70$ & $25 \%$ & $65 \%$ \\
DEP. ESTADUAL & 10.675 & $111.041,60$ & 47.922 & $156.053,14$ & $22 \%$ & $71 \%$ \\
DEP. DISTRITAL & 482 & $130.771,65$ & 2.243 & $143.949,53$ & $21 \%$ & $91 \%$ \\
PRESIDENTE & 22 & $50.573,28$ & 134 & $87.387,63$ & $16 \%$ & $58 \%$ \\
\hline
\end{tabular}

Fonte: Dados da Pesquisa

Importa destacar que o menor valor médio de bens refere-se aos candidatos à presidência da República, o que não indica que sejam esses os candidatos de maior patrimônio, tão somente podem possuir maior quantidade de bens declarados em valores inferiores aos demais, ou um patrimônio mais fracionado em diversos itens.

Outra característica do candidato é a regionalidade, consubstanciado no Estado de concorrência ao cargo. A amostra de dígitos discrepantes apresenta como candidatos com bens de maior valor entre os alvos da pesquisa, é o estado Tocantins, seguido do Ceará e de Rondônia, com bens de valor médio de $\mathrm{R} \$ 336.699,43$, $\mathrm{R} \$ 219.219,80$ e $\mathrm{R} \$ 207.768,40$, respectivamente, demonstrando que não há uma relação direta com o nível de desenvolvimento da unidade da federação.

Os bens dos candidatos do Estado do Tocantins apresentam maiores valores médios no âmbito dos dígitos discrepantes 3 e 5, e no universo de todos os dígitos. Além de apresentar os maiores valores nos dois cenários, os candidatos do Estado do Tocantins são os que apresentam maior discrepância entre a média dos bens dos dígitos 3 e 5 em relação ao universo de todos os dígitos, numa proporção de apenas $21 \%$ dos valores médios globais, ou seja, uma diferença de $79 \%$. 
Tabela 12 - Amostra dígitos excedentes por Unidade da Federação

\begin{tabular}{|c|c|c|c|c|c|c|}
\hline \multirow[b]{2}{*}{ UF } & \multicolumn{2}{|c|}{ Amostra Dígitos 3 e 5} & \multicolumn{2}{|c|}{ Todos os Bens } & \multicolumn{2}{|c|}{ Relação Amostra / Total } \\
\hline & Qtd & Média (R\$) & Qtd & Média (R\$) & $\%$ Qtd. & \% Val. Med. (R\$) \\
\hline TO & 372 & $336.699,43$ & 1.650 & $1.621 .325,01$ & $23 \%$ & $21 \%$ \\
\hline SE & 204 & $138.790,08$ & 909 & $336.818,06$ & $22 \%$ & $41 \%$ \\
\hline PR & 1.138 & $142.958,09$ & 5.323 & $310.550,49$ & $21 \%$ & $46 \%$ \\
\hline $\mathrm{AL}$ & 271 & $114.193,14$ & 1.142 & $310.351,84$ & $24 \%$ & $37 \%$ \\
\hline $\mathrm{CE}$ & 636 & $219.219,80$ & 2.892 & $290.779,69$ & $22 \%$ & $75 \%$ \\
\hline MG & 1.678 & $177.120,73$ & 7.481 & $250.176,46$ & $22 \%$ & $71 \%$ \\
\hline MT & 525 & $198.019,58$ & 2.299 & $235.725,21$ & $23 \%$ & $84 \%$ \\
\hline RJ & 1.439 & $131.664,15$ & 6.699 & $194.942,09$ & $21 \%$ & $68 \%$ \\
\hline RO & 448 & $207.768,40$ & 1.883 & $194.635,20$ & $24 \%$ & $107 \%$ \\
\hline GO & 808 & $158.827,37$ & 3.641 & $163.437,43$ & $22 \%$ & $97 \%$ \\
\hline ES & 423 & $116.312,90$ & 2.119 & $163.277,87$ & $20 \%$ & $71 \%$ \\
\hline DF & 701 & $149.355,17$ & 3.230 & $156.671,30$ & $22 \%$ & $95 \%$ \\
\hline AM & 371 & $183.536,65$ & 1.523 & $151.624,53$ & $24 \%$ & $121 \%$ \\
\hline $\mathbf{R R}$ & 296 & $113.288,69$ & 1.239 & $151.149,43$ & $24 \%$ & $75 \%$ \\
\hline MA & 551 & $121.289,35$ & 2.486 & $136.840,89$ & $22 \%$ & $89 \%$ \\
\hline $\mathrm{AC}$ & 265 & $83.940,27$ & 1.122 & $131.409,64$ & $24 \%$ & $64 \%$ \\
\hline RN & 307 & $136.862,89$ & 1.364 & $127.912,15$ & $23 \%$ & $107 \%$ \\
\hline MS & 549 & $134.184,39$ & 2.526 & $126.987,78$ & $22 \%$ & $106 \%$ \\
\hline PA & 608 & $120.084,94$ & 2.737 & $122.996,99$ & $22 \%$ & $98 \%$ \\
\hline BR & 43 & $83.117,15$ & 218 & $122.983,23$ & $20 \%$ & $68 \%$ \\
\hline BA & 790 & $154.102,78$ & 3.588 & $121.900,52$ & $22 \%$ & $126 \%$ \\
\hline $\mathrm{SP}$ & 2.953 & $120.933,67$ & 13.345 & $120.598,53$ & $22 \%$ & $100 \%$ \\
\hline PE & 508 & $124.623,01$ & 2.255 & $115.056,96$ & $23 \%$ & $108 \%$ \\
\hline $\mathbf{A P}$ & 214 & $111.929,93$ & 924 & $101.484,03$ & $23 \%$ & $110 \%$ \\
\hline $\mathrm{SC}$ & 746 & $87.680,39$ & 3.354 & $98.555,01$ & $22 \%$ & $89 \%$ \\
\hline PB & 368 & $110.282,12$ & 1.636 & $96.876,30$ & $22 \%$ & $114 \%$ \\
\hline RS & 882 & $75.734,37$ & 4.108 & $82.984,00$ & $21 \%$ & $91 \%$ \\
\hline PI & 288 & $76.185,18$ & 1.361 & $72.043,92$ & $21 \%$ & $106 \%$ \\
\hline
\end{tabular}

Fonte: Dados da Pesquisa

A última característica é possivelmente mais relevante por estar diretamente relacionada aos bens, o tipo de bem. A maior média de valores refere-se às licenças e concessões especiais, com valor médio declarado ao TSE, de R \$ 1.334.500,00, seguido de aeronaves em valor médio de $\mathrm{R} \$$ $872.665,95$.

Outro bem que destaca-se pela sua natureza é dinheiro em espécie, declarados em moeda nacional por 550 candidatos com valor médio de $R \$ 136.956,90$, e em moeda estrangeira por 28 candidatos em valor médio correspondente a $\mathrm{R} \$ 61.476,45$. Na variação quantitativa de itens, destacam-se as licenças e concessões especiais, que no recorte discrepante alcança $44 \%$ do universo, mas que se fundamenta numa quantidade muito pequena de itens, 4 .

Por tratar-se do tipo, que se relaciona diretamente ao objeto de investigação, os bens, intencionalmente foram selecionados todos os tipos de bem com média de valor do recorte superior a média do universo para análise prévia. 
Tabela 13 - Amostra dígitos excedentes por tipo de bem

\begin{tabular}{|c|c|c|c|c|c|c|}
\hline \multirow[b]{2}{*}{ Tipo_Bem } & \multicolumn{2}{|c|}{$\begin{array}{c}\text { Amostra Dígitos } 3 \mathrm{e} \\
5\end{array}$} & \multicolumn{2}{|c|}{ Todos os Bens } & \multicolumn{2}{|c|}{ Rel. Amostra / Total } \\
\hline & Qtd & Média (R\$) & Qtd & Média (R\$) & Rel. \% Qtd & Rel. \% Val. Med. (R\$ \\
\hline Recorte da Amostra & & & & & & $>100 \%$ \\
\hline Aeronave & 12 & $872.665,95$ & 67 & $670.835,28$ & $18 \%$ & $130 \%$ \\
\hline Licença e concessões especiais & 4 & $1.334 .500,00$ & 9 & $638.333,33$ & $44 \%$ & $209 \%$ \\
\hline Prédio residencial & 57 & $317.604,77$ & 250 & $270.908,56$ & $23 \%$ & $117 \%$ \\
\hline Prédio comercial & 121 & $345.528,78$ & 551 & $263.917,56$ & $22 \%$ & $131 \%$ \\
\hline Outros bens e direitos & 1 & $350.000,00$ & 6 & $254.001,19$ & $17 \%$ & $138 \%$ \\
\hline Outras particip. societárias & 266 & $338.315,44$ & 1.211 & $249.042,86$ & $22 \%$ & $136 \%$ \\
\hline Apartamento & 1.166 & $271.346,19$ & 6.060 & $231.466,76$ & $19 \%$ & $117 \%$ \\
\hline Bem exercício ativ. autônoma & 45 & $364.693,51$ & 162 & $215.635,98$ & $28 \%$ & $169 \%$ \\
\hline Depósito bancário no exterior & 14 & $491.628,58$ & 65 & $210.817,02$ & $22 \%$ & $233 \%$ \\
\hline Outras aplic. e Investimentos & 381 & $195.338,77$ & 1.831 & $186.150,62$ & $21 \%$ & $105 \%$ \\
\hline $\begin{array}{l}\text { Joia, quadro, objeto de arte, de coleção, } \\
\text { antiguidade, etc. }\end{array}$ & 64 & $322.149,77$ & 306 & $155.683,97$ & $21 \%$ & $207 \%$ \\
\hline Dinheiro em espécie nacional & 550 & $136.956,90$ & 2.248 & $133.837,39$ & $24 \%$ & $102 \%$ \\
\hline Fundo de investimento & 129 & $183.744,45$ & 593 & $124.882,20$ & $22 \%$ & $147 \%$ \\
\hline Dinheiro espécie estrangeira & 28 & $61.476,45$ & 129 & $56.325,12$ & $22 \%$ & $109 \%$ \\
\hline Consórcio não contemplado & 125 & $42.786,00$ & 601 & $39.032,53$ & $21 \%$ & $110 \%$ \\
\hline Depósito bancário no País & 1.206 & $33.010,30$ & 6.003 & $29.345,93$ & $20 \%$ & $112 \%$ \\
\hline Fundo de capitalização & 160 & $42.378,48$ & 681 & $28.023,63$ & $23 \%$ & $151 \%$ \\
\hline Título de clube e assemelhado & 52 & $17.004,26$ & 262 & $11.723,00$ & $20 \%$ & $145 \%$ \\
\hline Linha telefônica & 119 & $2.261,34$ & 526 & $2.005,74$ & $23 \%$ & $113 \%$ \\
\hline
\end{tabular}

Fonte: Dados da Pesquisa

Nos bens descritos com ocorrência superior à esperada, destaca-se que alguns tem tipologia comum a bens conhecidamente empregados em lavagem de dinheiro, como recursos em espécie, joias e obras de arte (Dallagnol, 2011).

Retomando aos procedimentos anteriores, a aplicação de NB revelou divergências nos dígitos 3 e 5 (Nigrini, 1992). Para detalhamento dos itens de análise, seguindo a análise de relevância de variações de quantidades e valores (Bugarin \& Cunha, 2015), foram identificadas as maiores variações para bens de candidatos do gênero masculino, de origem indígena, com formação de nível fundamental incompleto, concorrendo ao cargo de senador, pelo Estado do Tocantins, para diversos tipos de bens listados no quadro anterior.

A aplicação de filtros com todas essas características poderia apontar bens com elevado potencial de valores de primeiro dígito incorretos ou fraudulentos e seus detentores candidatos, ou mesmo bens declarados corretamente. Fato é que trata-se de sinalização de potenciais divergências, e o rastro desses sinais pode auxiliar o investigador e o auditor a encontrar as efetivas inconsistências.

$\mathrm{Na}$ presente amostra de bens de primeiros dígitos 3 e 5, inconsistentes com NB (Nigrini, 1992), a aplicação de todos esses critérios não revela existência de qualquer bem, o que demandou o relaxamento sistemático de diversos critérios. Por fim, mantidas as condicionantes de tipos de bens (Aeronave, Licença e concessões especiais, Prédio residencial, Prédio comercial, Outros bens e direitos, Outras participações societárias, Apartamento, Bem relacionado com o exercício da atividade autônoma, Depósito bancário em conta corrente no país e no exterior, Outras aplicações e Investimentos, Joia, quadro, objeto de arte, de coleção, antiguidade, Dinheiro em espécie - moeda 
nacional ou estrangeira, Fundo de investimento financeiro - FIF, Consórcio não contemplado, Fundo de capitalização, Título de clube e assemelhado, Linha telefônica) e de escolaridade (Ensino Fundamental Incompleto) revelam-se 26 ativos, que totalizam $\mathrm{R} \$ 2.779 .941,76$, descritos na Tabela 14.

Tabela 14 - Itens sinalizados por critérios Tipo de Bem e Escolaridade

\begin{tabular}{lccc}
\hline \multicolumn{1}{c}{ Tipo_Bem } & Qtd & Média (R\$) & Soma (R\$) \\
\hline Apartamento & 5 & $77.706,12$ & $388.530,58$ \\
Outras aplicações e Investimentos & 1 & 30,60 & 30,60 \\
Dinheiro em espécie - moeda estrangeira & 1 & $50.000,00$ & $50.000,00$ \\
Prédio residencial & 2 & $252.500,00$ & $505.000,00$ \\
Outras participações societárias & 1 & $5.040,00$ & $5.040,00$ \\
Consórcio não contemplado & 1 & $35.362,08$ & $35.362,08$ \\
Prédio comercial & 3 & $205.746,83$ & $617.240,50$ \\
Dinheiro em espécie - moeda nacional & 12 & $98.228,17$ & $1.178 .738,00$ \\
\hline \multicolumn{2}{c}{ Soma } & $\mathbf{2 6}$ & $\mathbf{2 . 7 7 9 . 9 4 1 , 7 6}$ \\
\hline
\end{tabular}

Fonte: Dados da Pesquisa

A partir da aplicação dos critérios indicados, do universo de 82 mil itens declarados de candidatos, resultaram 26 bens, permite uma análise individual de cada ativo, como avaliação, origem e aplicação, cadeia de custódia e registro legal, o que facilita (viabiliza) aos órgãos de controle e ao cidadão o efetivo controle jurídico e social sobre os candidatos a cargos eletivos.

Analisando a amostra à distância na perspectiva de pesquisa, em que $50 \%$ dos recursos são representados por 'dinheiro em espécie' em moeda nacional ou estrangeira, seria possível lançar suspeição sobre tais itens constantes da Tabela 15. Ao menos 10 candidatos declararam possuir pelo menos a quantia $\mathrm{R} \$ 30.000,00$ em espécie. A despeito, a grande maioria obteve como resultado a suplência de eleito, o que garante a possibilidade de posse futura.

Tabela 15 - Amostra sinalizada

\begin{tabular}{lccccc}
\hline \multicolumn{1}{c}{ Bem Declarado } & UF & Cargo & Partido & Valor (R\$) & Situação Candidatura \\
\hline Dinheiro em espécie - moeda nacional & SC & DEP. ESTADUAL & PMDB & $550.000,00$ & SUPLENTE \\
Dinheiro em espécie - moeda nacional & SC & DEP. ESTADUAL & DEM & $320.000,00$ & ELEITO POR QP \\
Dinheiro em espécie - moeda nacional & RO & DEP. ESTADUAL & PTB & $55.000,00$ & SUPLENTE \\
Dinheiro em espécie - moeda nacional & MG & DEP. ESTADUAL & PEN & $50.000,00$ & SUPLENTE \\
Dinheiro em espécie - moeda nacional & RO & DEP. ESTADUAL & DEM & $50.000,00$ & SUPLENTE \\
Dinheiro em espécie - moeda estrang. & RS & DEP. ESTADUAL & PP & $50.000,00$ & SUPLENTE \\
Dinheiro em espécie - moeda nacional & RS & DEP. ESTADUAL & PRB & $50.000,00$ & SUPLENTE \\
Dinheiro em espécie - moeda nacional & RO & DEP. ESTADUAL & PP & $35.000,00$ & SUPLENTE \\
Dinheiro em espécie - moeda nacional & MT & DEP. FEDERAL & PROS & $30.000,00$ & SUPLENTE \\
Dinheiro em espécie - moeda nacional & SP & 10 SUPLENTE & PRP & $30.000,00$ & NÃO ELEITO \\
Dinheiro em espécie - moeda nacional & RS & DEP. FEDERAL & PC do B & $5.000,00$ & SUPLENTE \\
Dinheiro em espécie - moeda nacional & PA & DEP. ESTADUAL & PPS & $3.400,00$ & SUPLENTE \\
Dinheiro em espécie - moeda nacional & PR & DEP. ESTADUAL & PTN & 338,00 & NÃO ELEITO \\
\hline Total & & & & $\mathbf{1 . 2 2 8 . 7 3 8 , 0 0}$ &
\end{tabular}

Fonte: Dados da Pesquisa 
No atual cenário parece inviável a guarda de recursos significativos em espécie (média de $\mathrm{R} \$ 98.228,17)$, pois os meios eletrônicos de pagamento permitem liquidez praticamente imediata; a guarda gera custo de oportunidade pois poderia estar aplicado em investimentos de pronto resgate e sem risco de crédito, como a poupança, e a perda do valor econômico pela inflação; e principalmente a 'insegurança' pública devido aos elevados índices de violência no Brasil, entre os quais roubos e furtos. Exceto uma das ocorrências, as demais podem também ser tipificadas nas red flags de fraudes atribuídas por Nigrini (2016), decorrente de grandes números inteiros, ou 'arredondados'.

A manutenção de elevadas somas de dinheiro habitualmente é reconhecida como tipologia típica de lavagem de dinheiro. Dallagnol (2011) destaca que o dinheiro em espécie é a principal forma como os ativos ilícitos são gerados e proporcionam o anonimato, pois a simples inclusão desses recursos no sistema financeiro seria manobra arriscada frente à regulamentação de prevenção à lavagem de dinheiro existente no setor bancário.

Outra tipologia indicada para a declaração de recursos em espécie, é a denominada 'fabricação de caixa fictício' que é uma "técnica comum utilizada por lavadores como por sonegadores é incrementar [...] o valor de suposta (fictícia) quantia mantida em espécie, com o titular [...] os quais poderão ser substituídos por bens ou valores que são oriundos de crimes" (Dallagnol, 2011, p. 339). Essa tipologia no cenário eleitoral proporciona o conhecido 'caixa 2' pois candidatos relatam guardar quantias ficcionais de recursos em casa que poderiam ser usados para justificar doação própria na prestação de contas, caso surja recurso com origem não identificada ou não permitida (Neitsch \& Silva, 2014). Por sua natureza de meio de pagamento, transações com dinheiro em espécie podem ser realizadas sem deixar rastro causando solução de continuidade no paper trail (Dallagnol, 2015).

Esse universo de bens com valores amostrais iniciados com dígitos 3 e 5, em ocorrências superiores às esperadas podem indicar um gerenciamento de valores de bens declarados, devendo ser objeto de análise mais aprofundada, seja pelos órgãos de controle, da imprensa, e principalmente na perspectiva dos eleitores.

\section{CONSIDERAÇÕES FINAIS}

No intuito de analisar a possibilidade de identificação de bens com indícios de inconsistências ou de origem suspeita entre o patrimônio declarado dos candidatos a cargo eletivo, foram realizados procedimentos estatísticos multivariados para identificar no universo de bens declarados, bens de origem ou declaração suspeitos. Para isso, a pesquisa declarou como objetivo identificar sinalizadores de distorções patrimoniais nos bens declarados pelos candidatos a cargos públicos a partir da aplicação da Lei Newcomb-Benford e da análise das divergências de médias.

A análise dos bens declarados pelos candidatos a cargos eleitorais por meio da verificação do primeiro dígito dos valores de cada bem pode indicar sinalizadores para desdobramentos de investigações. O modelo aplicado demonstrou-se útil com a Lei NB, que a partir do teste $\mathrm{Z}$ indicou distribuição dos valores com primeiro dígito divergentes ao esperado pela teoria em seis casos, posteriormente reduzidos a dois, devido a natureza positiva, ou adicional ao esperado, corroboradas pelo Fator de Distorção e pela Média dos Desvios Absolutos.

A partir da sinalização indicada pela aplicação do teste $Z$, entre as distribuições teórica e real, foi possível empregar maior esforço para analisar descritivamente os dados, em suas características próprias ou de seus declarantes, complementada pela análise da variação dos quantitativos e valores de média.

Nos achados desta pesquisa foi possível identificar, nos dígitos com ocorrências excedentes, características atípicas da normalidade do conjunto geral de dados que pode denotar indicação de 
suspeição sobre a efetiva correção dos dados. Pela ordem, nos dígitos discrepantes e excedentes da probabilidade da Lei NB, 3 e 5, identificou-se com elevada variação os bens de candidatos do gênero masculino, de origem indígena, com formação de nível fundamental incompleto, concorrendo ao cargo de senador, pelo Estado do Tocantins.

Em relação às características individualizadas dos bens, percebeu-se a significativa participação nas licenças e concessões com maior quantidade e valor médio, nas aeronaves com menor participação quantitativa e maior valor médio, e maior valor médio em depósitos em contas no exterior, quadros e joias raras, fundos de capitalização e títulos de clubes, bem como os valores em espécie em moeda nacional e estrangeira.

A aplicação dos critérios individualmente tende a evidenciar situações e bens, que incorrem em situações de bens declarados com características de transações típicas de operações de lavagem de dinheiro, como os recursos em espécie, em montantes significativos.

Pela própria natureza da pesquisa, a limitação deve-se a seu objetivo exploratório apresentando sinalizadores de suspeição, tão somente, e não uma determinação de que se trata de bens ou candidatos em condições de ilicitudes. Eventual indicação dependeria de um aprofundamento maior de pesquisas e investigações dependentes de atuação dos órgãos de fiscalização e controle.

Como sugestão de pesquisas futuras, indica-se a necessidade de avanço para demais eleições em nível federal e estadual, para identificar resultados mais robustos ou para comparar suas distribuições. Além disso, é possível que outros testes de distribuição de frequência possam apresentar outras evidências, como teste do segundo dígito, dos dois dígitos, e da soma dos dígitos. São relevantes também pesquisas relacionadas com dados das campanhas municipais que podem ter comportamentos distintos pela capilaridade dos candidatos, além relação com os dados de receitas e despesas eleitorais, na busca de indícios de fraudes eleitorais.

\section{REFERÊNCIAS}

Avis, E., Ferraz, C., \& Finan, F. (2016). Do government audits reduce corruption? Estimating the impacts of exposing corrupt politicians. Journal of Political Economy, 126(5), 1912-1964. https://doi.org/10.3386/w22443

Avis, E., Ferraz, C., Finan, F., \& Varjão, C. (2017). Money and politics: The effects of campaign spending limits on political competition and incumbency advantage. National Bureau of Economic Research Working Paper, 23508(w), 1-41. https://doi.org/10.3386/w23508

Barkemeyer, R., Preuss, L., \& Lee, L. (2015). Corporate reporting on corruption: An international comparison. Accounting Forum, 39(4), 349-365. https://doi.org/10.1016/j.accfor.2015.10.001

Barros, D. F., Sauerbronn, J. F. R., \& Ayrosa, E. A. T. (2012). Representações do eleitor: revendo teorias e propondo novos caminhos. Revista de Administração Pública, 46(2), 477-491. http://dx.doi.org/10.1590/S0034-76122012000200007

Benford, F. (1938). The law of anomalous numbers. Proceedings of the American philosophical society, 78(4), 551-572. Recuperado em 5 julho, 2018, de https://www.jstor.org/stable/984802

Bugarin, M.; Cunha, F. C. R. (2015). A didactic note on the use of Benford's Law in public works auditing, with an application to the construction of the Brazilian 'Amazon Arena' 2014 World Cup soccer stadium. エコノミア Economia, 66, 23-55. Recuperado em 9 julho, 2018, de https://ynu.repo.nii.ac.jp/

Bushman, R., Chen, Q., Engel, E., \& Smith, A. (2004). Financial accounting information, organizational complexity and corporate governance systems. Journal of Accounting and Economics, 37(2), 167-201. https://doi.org/10.1016/j.jacceco.2003.09.005

Carslaw, C. A. (1988). Anomalies in income numbers: Evidence of goal oriented behavior. Accounting Review, 321-327. Recuperado em 9 julho, 2018, de https://www.jstor.org/stable/248109 
Cella, R. S., \& Rech, I. J. (2017). Caso PETROBRAS: a Lei Benford Poderia Detectar a Fraude?. Revista de Gestão, Finanças e Contabilidade, 7(3), 86-104. Recuperado em 9 julho, 2018, de https://www.revistas.uneb.br/index.php/financ/article/view/3665

Christian, C. W., Gupta, S., \& Lin, S. (1993). Determinants of tax preparer usage: Evidence from panel data. National Tax Journal, 46(4), 487-503. Recuperado em 9 julho, 2018, de https://www.ntanet.org/NTJ/46/4/ntj-v46n04p487-503-determinants-tax-preparer-usage.pdf

Costa, J. I. D. F. (2012). Desenvolvimento de metodologias contabilométricas aplicadas à auditoria contábil digital: uma proposta de análise da lei de Newcomb-Benford para os Tribunais de Contas. Dissertação de mestrado, Universidade Federal de Pernambuco, Recife, PE, Brasil.

Costa, J. I. F., Dos Santos, J., \& Travassos, S. M. (2012). Análise de conformidade nos gastos públicos dos entes federativos: estudo de caso de uma aplicação da Lei de Newcomb-Benford para o primeiro e segundo dígito em dois estados brasileiros. Revista Contabilidade $\mathcal{E}$ Finanças-USP, 23(60). http://dx.doi.org/10.1590/S1519-70772012000300004

Dallagnol, D. M. (2011). Tipologias de lavagem. In C. V. Carli (Org.). Lavagem de dinheiro: prevenção e controle penal (pp. 289-362). Porto Alegre: Verbo Jurídico.

Dallagnol, D. M. (2015). As lógicas das Provas no Processo. Porto Alegre: Livraria do Advogado.

Diniz, J. A., Corrar, L. J., \& Slomski, V. (2010). Análise digital: uma abordagem cognitiva na detecção de não conformidade em prestações de contas municipais. Anais do Congresso USP de Controladoria e Contabilidade. São Paulo, SP, Brasil, 10. Recuperado em 5 janeiro, 2019, https://congressousp.fipecafi.org/anais/artigos102010/474.pdf

Dos Santos, J., Ribeiro Filho, J. F., Lagioia, U., Alves Filho, B. F., \& de Araújo, I. J. C. (2009). Aplicações da lei de Newcomb-Benford na auditoria tributária do imposto sobre serviços de qualquer natureza (ISS). Revista Contabilidade $\mathcal{E}$ Finanças, 20(49), 63-78. https://doi.org/10.1590/S1519-70772009000100006

Drake, P. D., \& Nigrini, M. J. (2000). Computer assisted analytical procedures using Benford's law. Journal of Accounting Education, 18(2), 127-146. https://doi.org/10.1016/S0748-5751(00)00008-7

Everett, J., Neu, D., \& Rahaman, A. S. (2007). Accounting and the global fight against corruption. Accounting, Organizations and Society, 32(6), 513-542. https://doi.org/10.1016/j.aos.2006.07.002

Ferraz, C., \& Finan, F. (2008). Exposing corrupt politicians: the effects of Brazil's publicly released audits on electoral outcomes. The Quarterly Journal of Economics, 123(2), 703-745. https://doi.org/10.1162/qjec.2008.123.2.703

Fux, L., \& Frazão, C. E. (2016). Novos paradigmas do direito eleitoral. Belo Horizonte: Editora Fórum.

Gil, A. C. (1999). Métodos e técnicas de pesquisa social. São Paulo: Atlas.

Healy, P., \& Serafeim, G. (2011). Causes and consequences of firm disclosures of anticorruption efforts. Harvard Business School Working Paper, 12-077, 1-43.

Horta, C. J. G., Dufloth, S. C., \& Freitas, D. R. R. (2016). Características socioeconômicas da população e de seus representantes eleitos nas assembleias legislativas brasileiras: análise de convergência entre perfis. Revista do Serviço Público, 67(4), 525-554. https://doi.org/10.21874/rsp.v67i4.989

Iudícibus, S. D., \& Marion, J. C. (2000). Introdução a teoria da contabilidade. São Paulo: Atlas.

Kassen, R., \& Higson, A. W. (2016). External auditors and corporate corruption: implications for external audit regulators. Current Issues in Auditing, 10(1), 1-10. https://doi.org/10.2308/ciia51391

Mattos, J. J. A., Mendes, B., \& de Oliveira Rios, D. (2012). Partidas dobradas: eleições 2012: contabilidade necessária. Brasília: CFC.

Murcia, F. D. R., Borba, J. A., \& Schiehll, E. (2008). Relevância dos red flags na avaliação do risco de fraudes nas demonstrações contábeis: a percepção de auditores independentes brasileiros. Revista Universo Contábil, 4(1), 25-45. http://dx.doi.org/10.4270/ruc.20084 
Nassmacher, K. H. (1992) Comparing party and campaign finance in western democracies. In A. Gunlicks (Ed.). Campaign and party finance in north America and western Europe. San Francisco: Wesview Press.

Neitsch, J., \& Silva, P. G. (2014). Candidatos dizem ter R\$ 5 mi em dinheiro vivo. Gazeta do Povo, Vida Pública. Recuperado em 28 dezembro, 2018, http://www.gazetadopovo.com.br/vidapublica/conteudo.phtml?id=1485424

Newcomb, S. (1881). Note on the frequency of use of the different digits in natural numbers. American Journal of mathematics, 4(1), 39-40. https://doi.org/10.2307/2369148

Nicolau, J. (2006). O sistema eleitoral de lista aberta no Brasil. Dados, 49(4), 689-720. https://dx.doi.org/10.1590/S0011-52582006000400002

Nigrini, M. J. (1992) The detection of income evasion through an analysis of digital distributions. $\mathrm{PhD}$ thesis, University of Cincinnati, Cincinnati, OH, USA.

Nigrini, M. J. (2000). Digital analysis using Benford's law. Vancouver: Global Audit Publications.

Nigrini, M. J. (2012). Benford's Law: Application for Forensic Accounting, Auditing and Fraud Detection. New Jersey: Wiley and Sons.

Nigrini, M. J. (2016). The implications of the similarity between fraud numbers and the numbers in financial accounting textbooks and test banks. Journal of Forensic Accounting Research, 1(1), A1-A26.

Pinkham, R. S. (1961). On the distribution of first significant digits. The Annals of Mathematical Statistics, 32(4), 1223-1230. https://doi.org/10.1214/aoms/1177704862

Rodrigues, L. F., \& Sallaberry, J. D. (2013). Aspectos legais e contábeis da prestação de contas eleitorais para as eleições de 2012: uma análise empírica à luz da legislação vigente. Revista Brasileira de Contabilidade, (199), 61-75. Recuperado em 5 dezembro, 2018, de http://rbc.cfc.org.br/index.php/rbc/article/view/1039

Sallaberry, J. D., Vendruscolo, M. I., \& Rodrigues, L. F. (2014). Receitas Eleitorais: da Teoria Contábil à Prática. ConTexto, 14(26), 56-65. Recuperado em 5 dezembro, 2018, de https://seer.ufrgs.br/ConTexto/article/view/43798/pdf_20

Santos, J. L. D., Schmidt, P., Gomes, J. M. M., \& Fernandes, L. A. (2004). Contabilidade geral. São Paulo: Atlas.

Santos, J., Diniz, J. A., \& Corrar, L. J. (2007). A Lei Newcomb-Benford. In L. J. Corrar, E. Paulo, \& J. M. Dias Filho (Coords.). Análise multivariada: para os cursos de administração, ciências contábeis e economia (pp. 506-541). São Paulo: Atlas.

Santos, J., Diniz, J. A., \& Ribeiro Filho, J. F. (2003). A Lei de Newcomb-Benford: uma aplicação para determinar o DNA-equivalente das despesas no setor público. Anais do Seminário USP de Contabilidade e Controladoria. São Paulo, SP, Brasil, 3.

Saville, A. D. (2006). Using Benford's law to detect data error and fraud: an examination of companies listed on the Johannesburg Stock Exchange: economics. South African journal of economic and management sciences, 9(3), 341-354. https://doi.org/10.4102/sajems.v9i3.1092

Vecchia, L. A. D., Mazzioni, S., Poli, O. L., \& Moura, G. D. (2018). Corrupção e Contabilidade: Análise Bibliométrica da Produção Científica Internacional. Sociedade, Contabilidade e Gestão, 13(3), 1-19. http://dx.doi.org/10.21446/scg_ufrj.v13i3.20033

Walker, J. (1999). How Big is Global Money Laundering?. Journal of Money Laundering Control, 3(1), 25-37. https://doi.org/10.1108/eb027208

Walliman, N. (2005). Your research project: a step-by-step guide for the first-time researcher. London: Sage.

Zovatto, D. (2005). Financiamento dos partidos e campanhas eleitorais na América Latina: uma análise comparada. Opinião Pública, 11(2), 287-336. http://dx.doi.org/10.1590/S010462762005000200002 